\title{
THE NATURE OF THE BREEDING SYSTEM IN THE FIELD BEAN (V. FABA L.) AND ITS RELATIONSHIP TO BREEDING FOR YIELD
}

\author{
D. G. ROWLANDS \\ Department of Agricultural Botany, University College of Wales, \\ Aberystwyth *
}

Received 22.v.57

THE field bean is one of the very few high protein grain crops which can be grown successfully on farms in Britain, and for this reason it is of great importance as a source of concentrated protein for livestock. However, in recent years it has become an extremely uncertain and unprofitable crop, and despite its potential usefulness is regarded with some mistrust. Over the past seventy years the acreage has fallen from approximately 450,000 acres to under 100,000 acres, and, according to the Agricultural Statistics for I882-I953, the average yield per acre has shown a slight decrease over the last twenty years. In comparison with cereal grain crops the yields per acre are generally poor.

The importance of the breeding system in relation to grain production has received little attention hitherto, and the precise nature of the breeding system itself has never been described. Until this situation is remedied, attempts at plant improvement can proceed only with difficulty.

Charles Darwin (I9oo) stated that bean plants which had been protected from insects gave one-third the number of pods which arc produced by unprotected plants; it was concluded therefore that $V$. faba was a naturally cross-pollinating species. Many other investigators remarked on the entomophilous nature of the bean flower and supported the suggestion that it was an outbreeding species. On the other hand, it has been shown that the proportion of crosspollination which takes place in the field is less than 50 per cent., and more often in the region of 30-40 per cent. (Fyfe and Bailey, I95 I ; Picard, I953), these results have prompted many to consider beans as generally self-fertilising (Reisch, I952).

A study of the cytology and floral mechanism in $V$. faba undertaken over the last few years has suggested an explanation of the apparently contradictory results previously obtained, and the implications of these findings for possible methods of improvement of the crop are discussed below.

The plant material used in these studies formed part of a Vicia collection, acquired from various sources. It consisted of 28 large-seeded and 18 small-seeded forms,

* Now at the Welsh Plant Breeding Station, Aberystwyth. 
but as the two types were indistinguishable cytologically and morphologically they were dealt with as one.

Pollen grain fertility was estimated on the basis of stainability with strong aceto-carmine/glycerol mixture. The glycerol was added to the aceto-carmine in equal proportion to reduce the movement of empty pollen grains to the edge of the coverslip.

Germination of pollen grains was carried out by the hanging drop method, with the ring unsealed and placed in a desiccator with a mixture of glycerine and water to adjust the hurnidity to approximately jo per cent. (Darlington and La Cour, 1947). Three different culture media were used namely, i 5 per cent. sucrose, style extract, and I part style extract to I part 15 per cent. sucrose. The style extracts were made by grinding a small number of styles in a drop of sterile distilled water using a tube and pestle (Glick, i 949 ).

Data on selfing individual plants with and without tripping were obtained by bagging the plants in fine cheese-cloth bags or in cheese-cloth cages.

\section{CYTOLOGICAL OBSERVATIONS}

A cytological survey of some 23 types of $V$. faba was undertaken using both root-tip and anther material. Fixations were made in Carnoy $(6: 3: 1)$, and aceto-carmine squash preparations were exclusively used. At mitosis, no irregularities were observed; the I 2 chromosomes appeared quite normal at metaphase, with the six pairs easily recognisable. Five pairs of chromosomes have a subterminal centromere, but the sixth pair is very much larger with a median centromere and a subterminal secondary constriction. This latter pair of chromosomes are the $M$ chromosomes of Maeda (i 930).

During meiosis, the mean chiasma frequency per bivalent observed in normal metaphases was $3.18 \pm 0.05(5.83 \pm 0.15$ for the $M$ chromosome), a comparatively high figure from the point of view of the recornbination index of the plant (Stebbins, 1950). Throughout the material investigated, normal metaphases (plate I, fig. I) were difficult to find, the frequency of irregularities which were observed being extremely high.

All the types so far examined showed abnormalities to a greater or lesser degree and under different environmental conditions, some of which appeared as early as diakinesis, but in most cases it was not until late metaphase I that they became obvious. However, when irregularities appeared during diakinesis they usually consisted of the stickiness often associated with fragments of varying size. The fragment could sometimes be associated with breakage of the large $M$ chromosome (text-figs. I, 2 ; plate I, figs. 6, 8) possibly at the weak points which exist in the heterochromatic regions as demonstrated by McLeish (1953). At metaphase, an upset in nucleic acid metabolism was inferred from overcontraction and more extreme forms of stickiness, but these phenomena, as stated previously, were comparatively rare (plate I, figs. 4,5 ).

At late metaphase/early anaphase, nearly all the cells in affected anthers looked abnormal. Uncoiling of the chromosome thread was very prevalent, and this was often associated with precocious separation 
of daughter centromeres and further fragmentation (plate I, fig. 9). This precocious separation of daughter centromeres frequently resulted

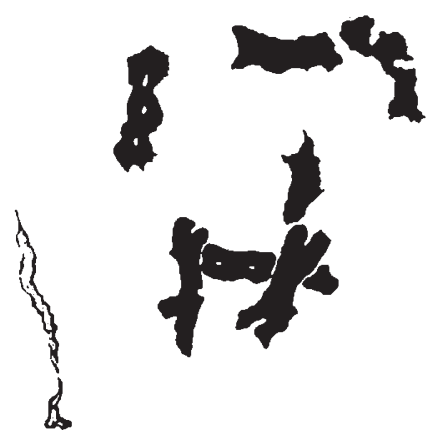

TExT-FIG, r.-Diakinesis showing heterochromatic fragment resulting from breakage during a pre-meiotic mitosis.

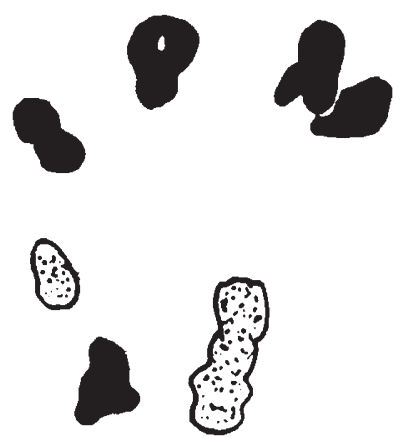

TExT-Fig. 2.-Metaphase showing overcontraction of the chromosomes and a fragment resulting from breakage of the $M$ chromosome.

in the formation of ring configurations presumably due to the continued association of opposite daughter chromatids (plate I, fig. 7). A normal anaphase arrangement followed by telophase did not occur; instead, the chromatids fell apart during late metaphase although thcy largely separated into two groups. At times, however, the only

TABLE I

Frequency of cytological irregularities in population plants of $\mathrm{V}$. faba

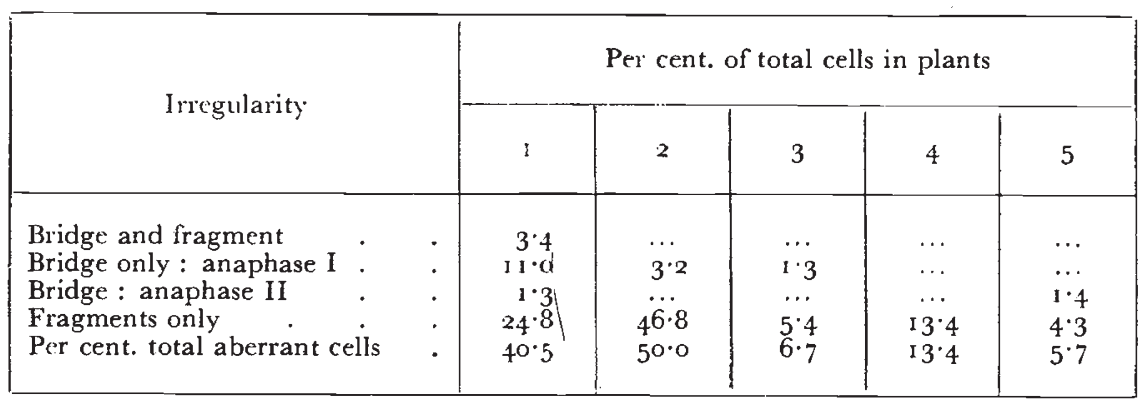

visible abnormalities were the bridges and fragments produced at anaphase.

Rees and Thompson (1955) have shown that bridges and fragments which occur in high frequency most probably result from splitting errors and genetically-controlled chromosome breakage. None the less, the possibility remains that at least some of the bridges which were accompanied by fragments may result from inversion heterozygosity (text-figs. 3,4 ). It was found that the $M$ chromosome was frequently involved in bridge formation as well as another sinall chromosome (text-figs. 5, 6: plate I, fig. 4), a fact which appears to confirm the suggestion that breakage and splitting errors are responsible here for many of the bridges at anaphase. Another feature of note 
was that in the artificially-produced autotetraploid, the irregularities proved to be of a more extreme form, which further emphasises their gene-controlled nature.
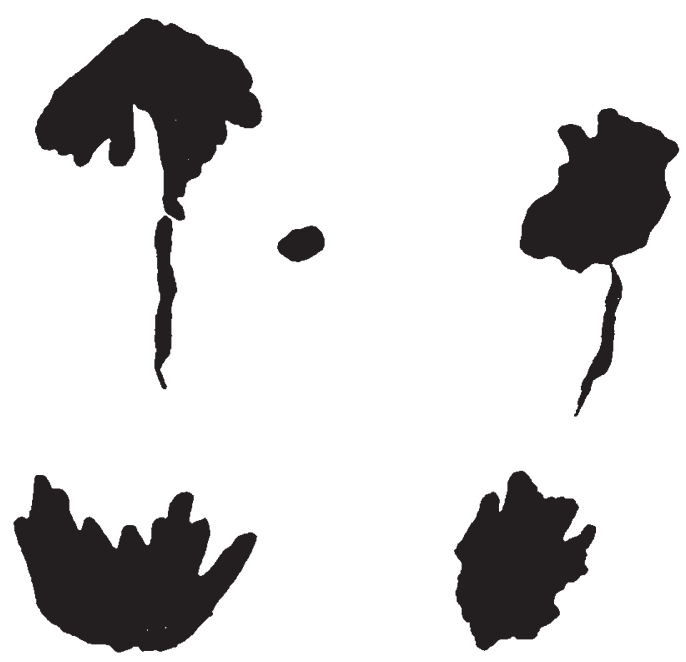

TEXT-FIGs. 3 and 4.-Anaphase bridges with accompanying fragments.

Pollen fertility in the flowers which reached maturity was between 8o-go per cent. although in some cases half the anthers appeared to be empty in an otherwise fertile flower.
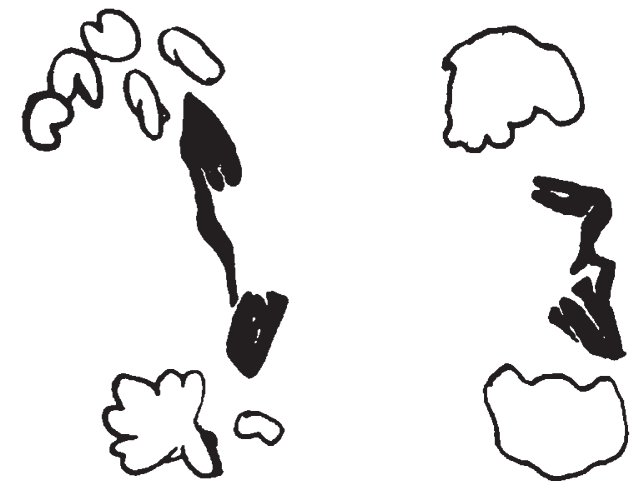

Text-Figs 5 and 6.-Anaphase bridges inrolving the $M$ chromosome but without fragnents.

\section{FLORAL MECHANISM}

An examination of the floral mechanism to obtain more critical information on the actual breeding system of beans showed the necessity for tripping to effect efficient seed production as originally demonstrated by Reisch (1952).

Tripping entails the release of the stigma and style from the keel of the flower where it has been retained under pressure. In the bean 
this mechanism results in the breakage of tiny papillæ on the stigma with consequent discharge of their contents. In lucerne also, tripping has been shown by Armstrong and White (1935) to result in similar damage of the stigmatic surface with the liberation of stigmatic

TABLE 2

The effect of tripping on pod-setting in $\mathrm{V}$. faba

\begin{tabular}{|c|c|c|c|c|}
\hline & & \multicolumn{2}{|c|}{ Number of } & \multirow{2}{*}{$\begin{array}{l}\text { Per cent. flowers } \\
\text { forming pods }\end{array}$} \\
\hline & & Flowers & Pods & \\
\hline No tripping-selfing & . & 215 & 5 & $2 \cdot 3$ \\
\hline Tripping-selfing . & . & 227 & 29 & $12 \cdot 4$ \\
\hline Open-pollinated & . & $846_{3}$ & 1957 & $23 \cdot 1$ \\
\hline
\end{tabular}

contents, thus enhancing germination and growth of foreign pollen as distinct from self pollen. A similar phenomenon appears to exist in beans as indicated by pollen germination tests conducted in culture media to which had been added aqueous style extracts. These tests were of a preliminary nature, but the results indicate that foreign pollen germinated and grew better than self pollen in the same style

TABLE 3

Pollen germination after 19 hours in artificial culture media

\begin{tabular}{|l|c|c|c|c|}
\hline \multirow{2}{*}{ Culture medium } & \multicolumn{2}{|c|}{$\begin{array}{c}\text { Pollen from the } \\
\text { same plant }\end{array}$} & \multicolumn{2}{|c|}{$\begin{array}{c}\text { Pollen from } \\
\text { different plant }\end{array}$} \\
\cline { 2 - 5 } & $\begin{array}{c}\text { Per cent. } \\
\text { germination }\end{array}$ & $\begin{array}{c}\text { Pollen-tube } \\
\text { growth }\end{array}$ & $\begin{array}{c}\text { Per cent. } \\
\text { germination }\end{array}$ & $\begin{array}{c}\text { Pollen-tube } \\
\text { growth }\end{array}$ \\
\hline Style extract \\
Style extract+sucrose
\end{tabular}

$$
\begin{aligned}
+ & =\text { germination beginning } \\
++ & =\text { slight pollen-tube growth } \\
+++ & =\text { pollen-tubes well grown }
\end{aligned}
$$

extract (table 3$)$. The $p \mathrm{H}$ of the medium was found to be a critical factor and was adjusted to that of the style extract, in this case $p \mathrm{H} 6 \cdot 5$.

It appears from these results that the stylar contents discriminate to some degree between the self and foreign pollen present on the stigma, and thus ensure cross-fertilisation.

On selfing the pod-setting capacity of the plants was poor so that even when artificial tripping was complete a low seed set was obtained. The value of pod-setting for individual plants varied a great deal, 
which suggests that in addition to the mechanical and pollen-tube selection for cross-fertilisation, some measure of genetic self-incompatibility appeared to exist.

\section{FLOWER FORMATION AND SEED-SETTING IN THE FIELD}

A study of pod formation in ro spring varieties of field beans was undertaken in order to assess the relative importance of flower and pod production for yield.

Seed of Io varieties was germinated in boxes in March; five. plants of each at the seedling stage being planted $2 \mathrm{ft}$. apart into.

TABLE +

Mean values for various components of yield in spring beans 1954

\begin{tabular}{|c|c|c|c|c|c|c|c|c|}
\hline \multirow{2}{*}{ Variety } & \multicolumn{2}{|c|}{ Mean number for } & \multirow{2}{*}{$\begin{array}{l}\text { ist pod } \\
\text { node }\end{array}$} & \multirow{2}{*}{$\begin{array}{l}\text { Height } \\
(\mathrm{cm} .)\end{array}$} & \multicolumn{3}{|c|}{ Mean number per plant } & \multirow{2}{*}{$\begin{array}{c}\text { Per cent. } \\
\text { flowers } \\
\text { forming } \\
\text { pods }\end{array}$} \\
\hline & $\begin{array}{l}\text { Days to } \\
\text { flowering }\end{array}$ & $\begin{array}{c}\text { Ist } \\
\text { flower } \\
\text { node }\end{array}$ & & & Tiller's & Flowers & Pods & \\
\hline A. $\mathrm{FM}_{\mathrm{I}} 6$ & $98 \cdot 9$ & $8 \cdot 6$ & $8 \cdot 9$ & $74^{\circ} 0$ & $5 \cdot 3$ & 198 & 25.5 & 14.0 \\
\hline B. Fmi 4 & $86 \cdot 8$ & $7 \cdot 4$ & $7 \cdot 9$ & $82 \cdot 2$ & 3.5 & 229 & $38 \cdot 6$ & $17 \cdot 0$ \\
\hline C. Fmg & $95^{\circ} 9$ & $7 \cdot 5$ & $7 \cdot 9$ & $72 \cdot 3$ & $3 \cdot 1$ & 154 & $32 \cdot 5$ & $20 \cdot 4$ \\
\hline D. Fmi 2 & $101 \cdot 7$ & $8 \cdot 3$ & $8 \cdot 5$ & $71 \cdot 8$ & $2 \cdot 9$ & 164 & $38 \cdot 8$ & $23 \cdot 2$ \\
\hline E. $\mathrm{Fm}_{13}$ & $95^{\cdot 1}$ & $8 \cdot 0$ & $9 \cdot 5$ & $72 \cdot 6$ & $2 \cdot 4$ & 163 & $26 \cdot 9$ & $12 \cdot 3$ \\
\hline F. Fmi I & $97 \cdot 3$ & $7 \cdot 9$ & $8 \cdot 3$ & $73 \cdot 3$ & $2 \cdot 6$ & 134 & $28 \cdot 7$ & $22 \cdot 8$ \\
\hline G. Fmio & $96 \cdot 3$ & $7 \cdot 6$ & $7 \cdot 7$ & 69.7 & $2 \cdot 8$ & 146 & $26 \cdot 7$ & $19 \cdot 6$ \\
\hline H. Fm4 & $80 \cdot 9$ & $5 \cdot 5$ & $6 \cdot 6$ & $47^{\circ} 4$ & $3 \cdot 4$ & 55 & $22 \cdot 6$ & $33 \cdot 2$ \\
\hline I. $\mathrm{FM}_{4}$ & $86 \cdot 5$ & $6 \cdot 3$ & $6 \cdot 7$ & $59 \cdot 2$ & $4 \cdot 1$ & 66 & $16 \cdot 7$ & $30 \cdot 9$ \\
\hline J. FM5 & $92 \cdot 5$ & $7 \cdot 2$ & $8 \cdot 0$ & $64: 2$ & $2 \cdot 6$ & $13^{8}$ & $25 \cdot 4$ & $19 \cdot 8$ \\
\hline Total mean & $93 \cdot 2$ & $7 \cdot 4$ & $8 \cdot 0$ & $68 \cdot 7$ & $3 \cdot 3$ & 145 & $28 \cdot 2$ & $21 \cdot 3$ \\
\hline S.E. . & $\pm r \cdot 2$ & \pm 0.3 & \pm 0.4 & $\pm 3 \cdot 2$ & \pm 0.5 & \pm 22 & not sig. & $\ldots$ \\
\hline
\end{tabular}

replicated rows $2 \mathrm{ft}$. wide. The period from germination to the opening of the first flower was measured in days, and was fairly consistent in each variety. Small tags of plastic wire were used to mark the flowers counted from week to week, only the total number being recorded; small aborted flowers were ignored, since the comparison required was that of the total functional flowers in relation to the actual number of pods set.

Conditions during the summer of 1954 were such that a high percentage of seeds in the lower pods germinated while still attached to the plant, and frequently when the pods were green. Seed-shedding took place in certain plants due possibly to alternating rainy and dry spells, so that between 40 and 50 per cent. of the total pods were not harvested, and about 20 per cent. of the plants did not survive until harvest as a result of damage by wind and mechanical breakagc. Mean value per plot was used in the data, therefore as only individual plants in each plot were lost they did not materially affect the analysis (table 4 ). 
The data suggest that pod number is largely, though not completely, independent of number of flowers ; however, once a sufficient number of flowers is produced pod formation appears to be influenced by other factors. Visitation by insects is random, and it would seem that

TABLE 5

Mean values and mean squares for yield and its components for once-grow'n versus original seed, 1955

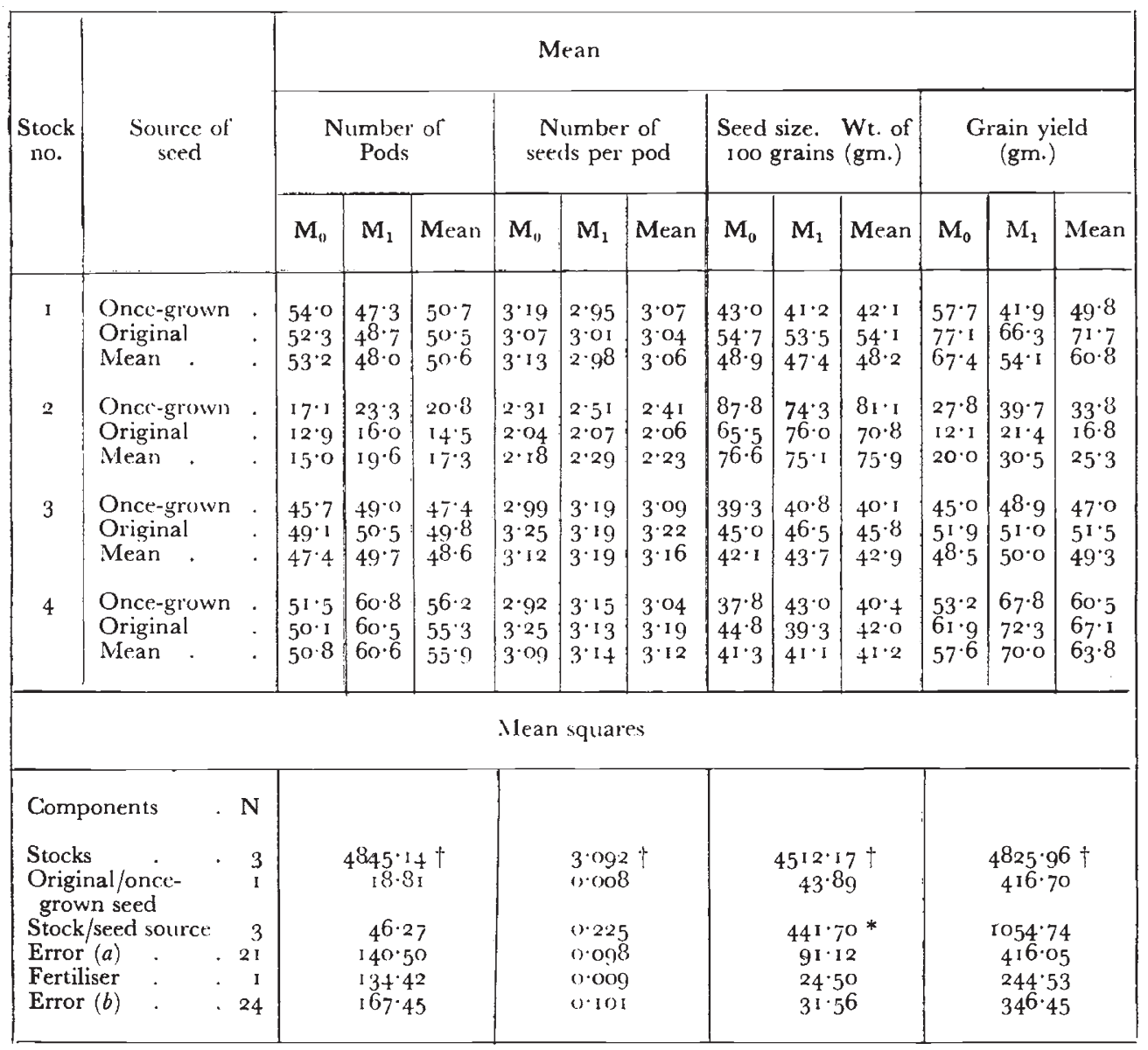

$\mathrm{M}_{0}=$ no fertiliser.

$M_{1}=5 \mathrm{cwt}$. complete fertiliser per acre.

* = significant at I per cent. level. $\dagger=$ significant at 0.1 per cent. level.

most differences in pod setting in plants may be due to their capacity for self-pollination and self-fertilisation.

\section{CROSS-POLLINATION AND BREEDING METHODS}

In all bean improvement programmes, the possibility exists of contamination of breeding material through cross-pollination. The extent and importance of this was investigated in 1955 , by comparing the open-pollinated progeny from the 1954 experiment with the original 
seed material. Four stocks, each represented by original and oncegrown seed were sown in randomised pairs of rows $2 \mathrm{ft}$. wide, alternating rows receiving the equivalent of $5 \mathrm{cwt}$. per acre complete fertiliser. Examination of the whole plot data showed that there were significant differences between stocks in all four characters measured (table 5 ).

The stock/secd source interaction mean square in respect of seed size was significant at the I per cent. level, but that for grain yield was not, although presumably the same tendency was exhibited.

The niean squares relating to treatment, and treatment/stock interaction calculated on the split-plot basis were not significant. Manurial treatments, therefore, did not appear to have any effect on pod number, seeds per pod, seed size, or yield of grain.

TABLE 6

Analysis of variance of regression: once-grown seed on initial seed

\begin{tabular}{|c|c|c|c|c|c|c|}
\hline & & $\begin{array}{l}\text { Sums of } \\
\text { squares }\end{array}$ & $x$ & $\begin{array}{c}\text { Mean } \\
\text { square }\end{array}$ & $\begin{array}{c}\text { Variance } \\
\text { ratio }\end{array}$ & Probability \\
\hline $\begin{array}{l}\text { Replication } \\
\text { Regression } \\
\text { Error . }\end{array}$ & $\begin{array}{l}. \\
. \\
.\end{array}$ & $\begin{array}{r}765 \cdot 86 \\
1840 \cdot 90 \\
\\
1024 \cdot 13\end{array}$ & $\begin{array}{l}3 \\
1 \\
\\
11\end{array}$ & 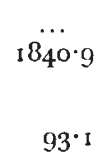 & $\begin{array}{c}\ldots \\
19 \cdot 8 \\
\ldots\end{array}$ & 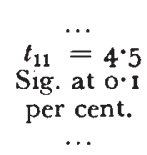 \\
\hline Total & . & $3630 \cdot 89$ & 15 & $\ldots$ & $\ldots$ & $\ldots$ \\
\hline \multicolumn{7}{|c|}{$Y=47 \cdot 72+0.41(x-\bar{x})$} \\
\hline
\end{tabular}

Further analysis of the effect of once-grown seed was undertaken using the regression of once-grown seed on initial seed. Taking grain yield, the equation for the regression line is $\mathrm{Y}=47 \cdot 72+0 \cdot 4 \mathrm{I}(x-\bar{x})$. This line was calculated from the varietal values over 4 replications, giving 16 pairs of values, instead of only 4 if the mean alone had been used. The significance of this regression line can be seen from table 6 where $t=4.5$, significant at 0.1 per cent. level.

If no significant difference existed between initial material and once-grown seed, the slope of the regression line should be unity and would theoretically pass through the origin. This line is shown in text-fig. 7 marked OZ. The regression line appears to be approaching the mean of the general population and deviates considerably from the expected line OZ.

The standard deviation of the difference between the regression coefficient and the theoretical one of unity is the same as the standard crror of that regression coefficient namely $0.093^{2}$, so that

$$
t_{11}=\frac{0.59}{0.093^{2}}=6.33
$$

which is significant at the I per cent. level. 
Consequently it can be said that the once-grown seed deviates significantly from the initial seed in grain yield in the general direction of the mean of the contiguous populations. This suggests that when grown in proximity to each other a high-yielding line would tend to degenerate in yield, and a low-yielding line to increase. The oncegrown seed used in the present test was obtained from the small rows of the previous year, and demonstrates the futility of using seed for experimental purposes which has not been isolated from other stocks. This equilibrium of populations growing together must result from

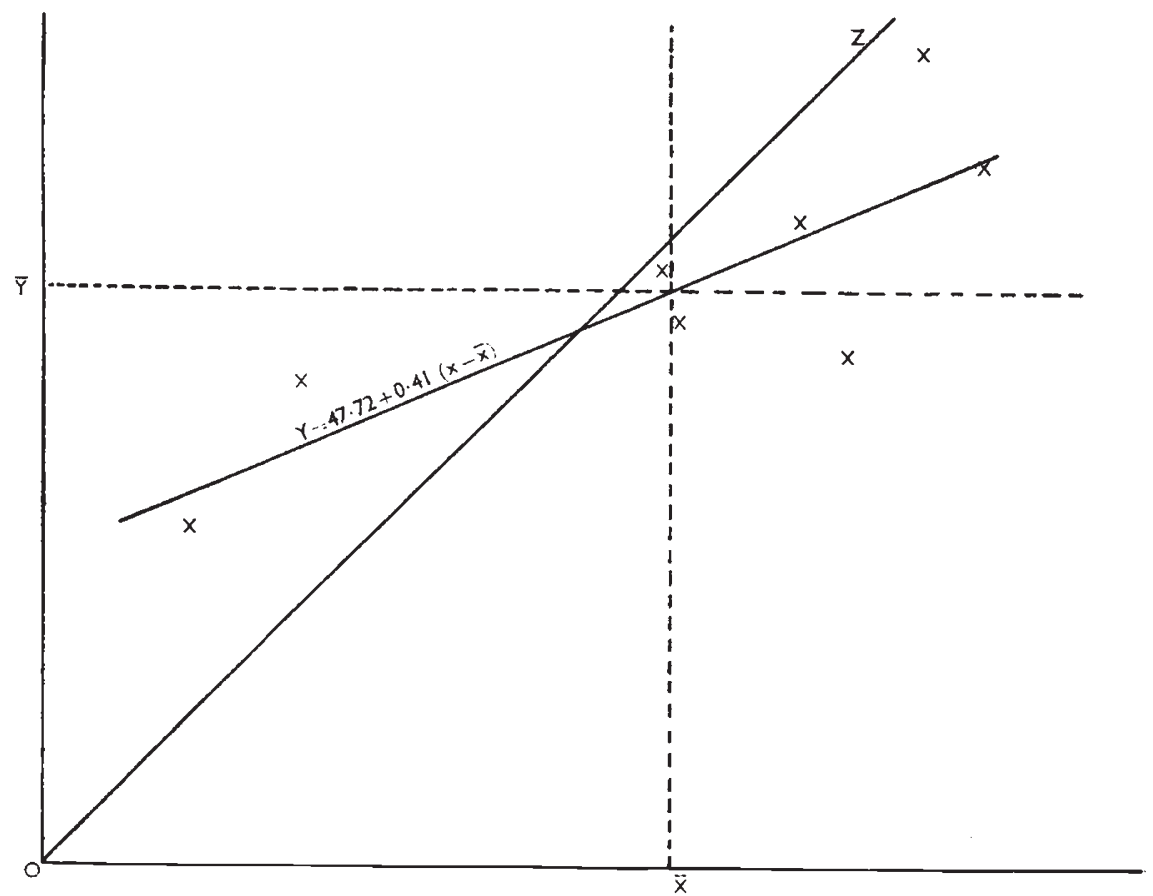

TEXT-FIG. 7.-Regression of once-grown seed on original seed in field bean.

cross-pollination, the effect of which would become apparent on introducing a new high-yielding line into a locality where yields are low, as in course of time the yield of the new line would fall to the general mean of the surrounding populations. This process was actually recorded nearly twenty-five years ago by Dr Hunter (Garner, 1945). who attributed it to cross-pollination between the new line and the existing populations.

Pod number does not appreciably alter under such conditions (table 5), and the number of seeds per pod does not show a significant difference when comparing original and once-grown seed. The only primary yield characteristic which appeared to be in any way highly heritable is seed size, and this was the only significant stock/seed source interaction noted. 


\section{DISCUSSION}

The cytological irregularities observed at meiosis in this crop are those previously associated with inbreeding in naturally outbreeding crops such as rye, and have been reported upon. The distribution and occurrence of these irregularities in Secale cereale have been discussed by Müntzing and Prakken (1941) and Akdik and Müntzing (1949) in population material, and by Lamm (1936), Müntzing and Akdik (1948) in the first generation of inbred rye. Rees (1955) has shown that these irregularities during meiosis are directly attributable to the effect of inbreeding the normally outbreeding rye plant. Similar irregularities have been described for inbred Alopecurus myosuroides (Johnsson, 1944). Bridges and fragments, spiralisation defects, and a general timing unbalance have been observed in Lathyrus odoratus material that had been inbred for a number of generations (Upcott, 1937).

The similarity between these observations described for Vicia faba and those recorded on other plants is striking. A normal inbreeding plant would not be expected to suffer any cytological ill-effects following inbreeding so that it may be concluded that $V$. faba is in fact an outbreeding species. Its relatively high chiasma frequency, which appears to confirm this, would in fact be disadvantageous in a normal inbred plant where fitness, rather than flexibility, is to be desired (Darlington and Mather, 1949).

Further evidence for the basically outbreeding nature of $V$. faba is provided by the studies on the floral mechanism. Although the pollen is shed before the flowers open, this is effectively neutralised by the necessity for tripping before the pollen is able to germinate. In nature, tripping is carried out by insects, and invariably involves the deposition of foreign pollen on the stigmas. Due to the faster growth of foreign pollen, cross-fertilisation would almost always result from natural tripping. Taken in conjunction with this differential pollen growth, the self- and cross-sterility which appear to exist in varying degrees suggest an incompatibility system of an incomplete nature. Such a system has been demonstrated in lucerne (Whitehead and Davis, 1954), but cannot be explained on the basis of major gene effects alone.

It can be seen from the analysis of the experimental data that a number of factors have an important bearing on yield as a whole. Yield expression in field beans can be separated into three main phases of development, firstly, the period in the development of the plant up to and including flower formation; secondly, the period from podsetting until maturation of the crop ; thirdly, the phase of pollination and fertilisation which link together the other two periods and which is of paramount importance for seed production.

The data obtained for the vegetative characters of the plant show that in general they are positively correlated with each other. This 
suggests that a strong and vigorous plant should also bear a large number of mature flowers, a feature borne out in the general observations. Pod formation, however, appears to be an independent process, and the crucial period must occur during pollination and fertilisation.

Although 6o-7o per cent. of the seeds produced are the result of sclf-fertilisation, the genetic system is adjusted to a high hybridity optimum and would therefore require a high rate of outcrossing for its efficient working. It can be seen, table 2, that in the field only 8-9 per cent. of the total flowers formed appear to have been tripped by insects, since only $30-40$ per cent. of those producing pods do so as a result of crossing. Either there is a shortage of tripping insects, duc to adverse weather conditions, or the insects which are present are unable successfully to trip the flowers. In Great Britain only the larger species of bumble bees (Bombus spp.) are capable of tripping bean flowers with any degree of efficiency, and even then there is a tendency for certain bees to pierce the base of the corolla and remove the nectar without tripping the flower. The difficulty in tripping bean flowers may have resulted from the unconscious selection through husbandry practice resulting in greater flower size which as a result became less well adapted for the pollinating insects to work. This difficulty also appears in lucerne and other papillionaceous flowers, and may be one of the factors influencing the change over to selffertilisation that has already occurred in Pisum and Phaseolus.

For the successful production of seed in beans the following four factors have to be considered :

(I) The inherent fertility of the plant. The basic capacity of any particular plant to produce seed is undoubtedly under polygenic control.

(2) The tripping mechanism. Until tripping has occurred pollen is unable to germinate, consequently insect visitation has to be chiefly relied upon for apprcciable pod formation.

(3) Differential pollen-tube growth. Foreign pollen appears to germinate and grow faster than self pollen, although in the absence of foreign pollen self pollen must sometimes grow down to fertilise the ovule.

(4) Incompatibility. In all probability both self- and cross-incompatibility operate to some degree, although possibly under polygenic control, but the participation of major genes in their control cannot be ruled out, Lundquist ( I 954, i 955).

Under natural conditions these factors are subject to many environmental influences, and at the same time quite probably interact with each other. Basic fertility, like any other quantitative character, can be influenced by manurial treatment and improved by selection and breeding. Nectar production has been shown in alfalfa to influence the frequency of insect visitation (Pedersen, I953), and therefore the degree and efficiency of tripping. The ideal, however, would be to 
eliminate dependence on insects by the selection of a self-tripping, highly self-fertile plant.

In a crop cultivated for its grain, the breeding system should allow the production of a relatively homogeneous product. An outbreeding system is less of a handicap when dealing with forage crops, but field beans occupy an intermediate position. Two alternatives are open to the breeder, either to persevere with selection methods suitable for outbreeding plants, with the attendant difficulties of isolation requirements, or attempt to change the breeding system towards that of a true inbreeding plant so that cereal breeding methods can be used. At present, in Vicia faba inbreeding is imposed on an outbreeding system, but it should be possible to complete the change over to inbreeding.

Inbreeding experiments with field beans (Griffiths and Rowlands, unpublished data) suggest that although the general vigour of a population may deteriorate following continued selfing, certain individual plants appear none the worse and set seed quite well in the absence of pollinating insects.

Enormous simplification of the breeding work in the bean crop would result from the development of a self-tripping, self-fertile variety as a basis for subsequent strain building since such material would self-pollinate in preference to cross-pollinating and could therefore be expected to set seed in the field without difficulty. The success of such a programme would not become immediately apparent and in the meantime improvement will have to proceed in the direction of winter-hardiness and a reduction of pod-shattering.

\section{SUMMARY}

I. A cytological examination of natural populations of field bcans revealed the widespread occurrence of irregularities during meiosis of a type previously associated with inbreeding depression in an outbreeding species.

2. The floral mechanism is adapted for cross-pollination and the differential pollen germination and growth in association with a weak incompatibility system suggests the limitation of self-fertilisation.

3. Under field conditions a major proportion of the seed produced results from self-fertilisation, the inadequacy of insect pollination forcing the plants to self with the consequent poor vield. It is thereforc assumed that inbreeding is superimposed on a naturally outbreeding system.

4. Despite the high degree of self-fertilisation normally encountered in the field, the effect of cross-pollination in contaminating breeding material by other pollen is considerable, thus increasing the difficulties inherent in any bean breeding programme.

5. Enormous simplification of breeding work in the bean crop would result from the development of a self-tripping, self-fertile line as a basis for subsequent strain building. 


\section{Plate I}

Fig. 1.-Normal metaphase of meiosis showing differences between $M$ and $m$ chromosomes.

FIG. 2.-Dividing nuclei showing stickiness due to nucleic acid.

FIG. 3.-Diakinesis showing fragment.

FIG. 4.-Early metaphase showing stickiness and extra chromosomes.

Fig. 5.-Stickiness and micronuclei during division.

Fig. 6.-Extra chromosome from breakage of the $M$ chromosome.

Fig. 7.-Precocious separation of daughter centromeres.

Fig. 8.-Early anaphase with heterochromatic fragment.

Fig. 9.-Separation of chromatids at first anaphase and uncoiling of the chromosome thread.

All figures $\times c a .2000$. 

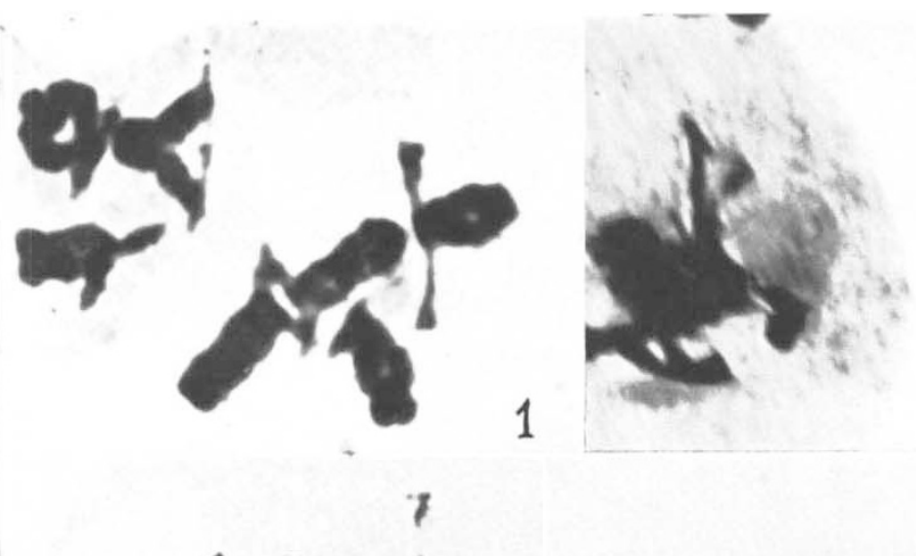

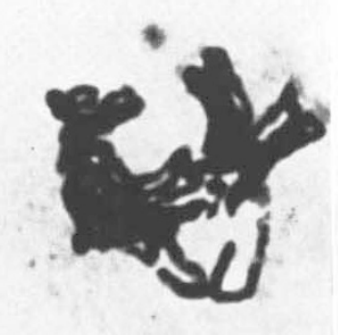

5

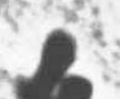

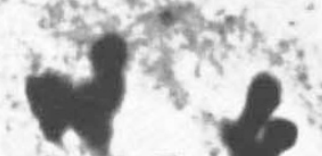

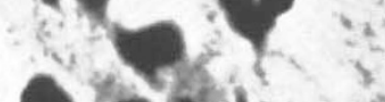

$6>0$.

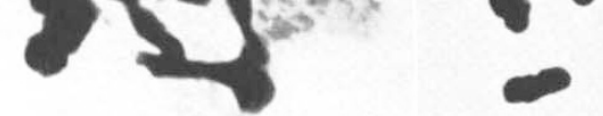

4

loting

$\underbrace{2}_{0}$

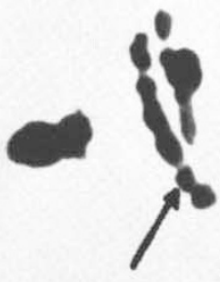

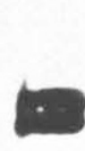

$\checkmark$

8
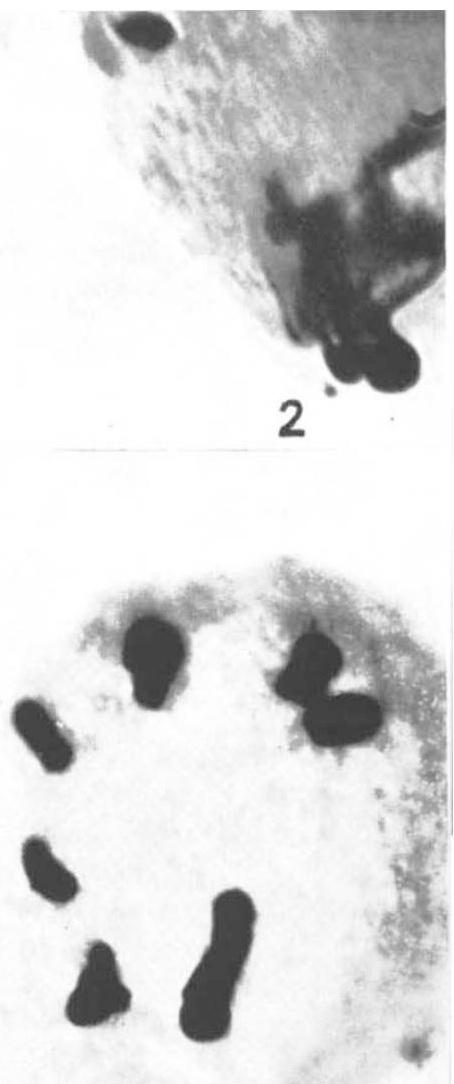

6<smiles>CCCCCC</smiles>

12

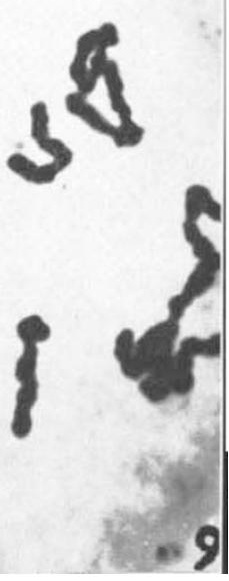




\section{Plate II}

Fig. 1.-Uncoiling of the chromosome thread and precocious separation of the chromatids.

Fig. 2.- Second anaphase immediately following the first, with uncoiling and separation of the chromatids.

Fig. 3.--Second anaphase with both $M$ chromosomes involved in bridge forniation.

FIg. 4.-First anaphase with bridges and heterochromatic fragments.

Fig. 5.-Micronuclei at second division.

Fig. 6.-Micronuclei at tetrad stage.

FIg. 7.-Second division bridge and micronuclei.

All figures $\times c a .2000$. 


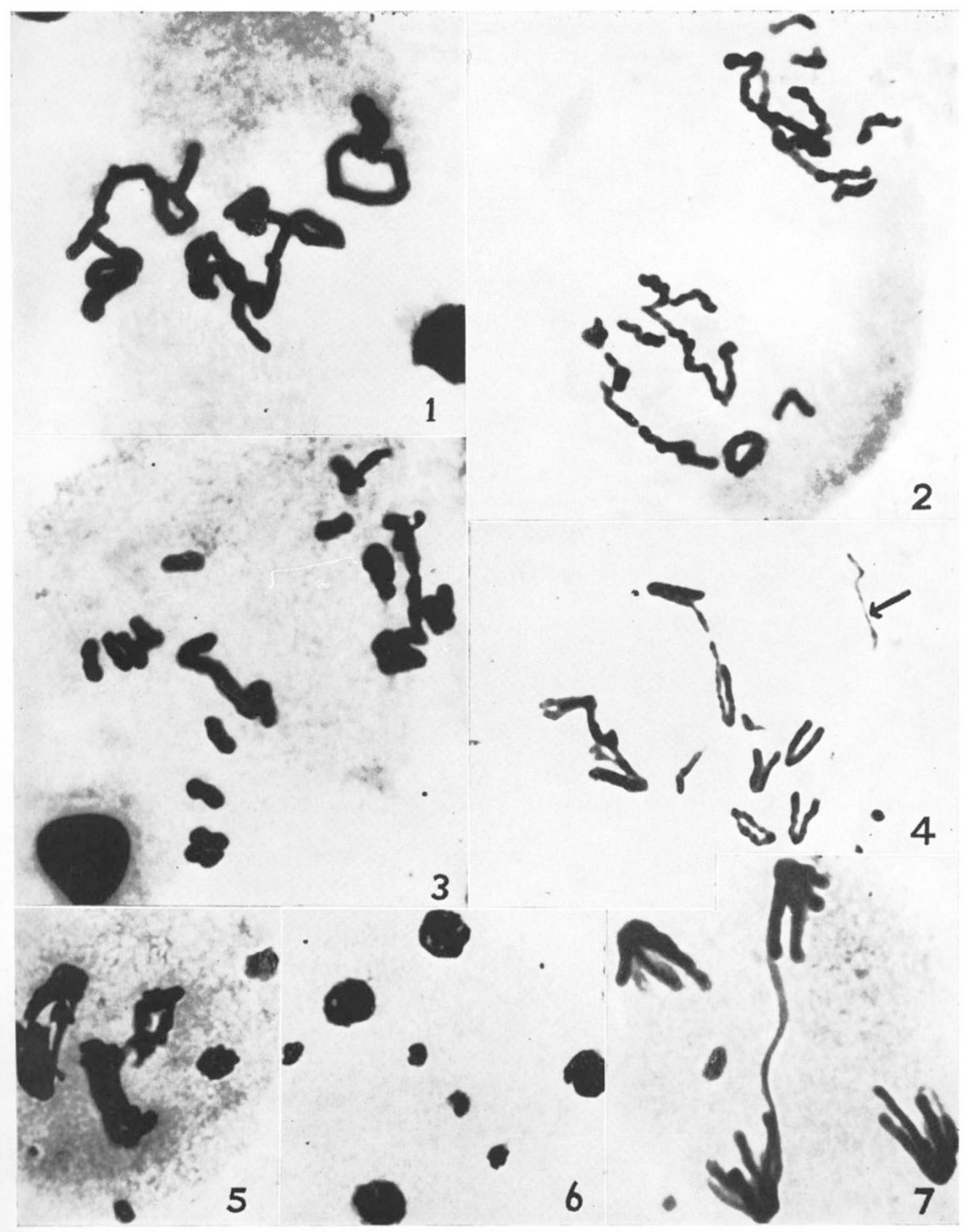


Acknowledgments.-I wish to thank the Agricultural Research Council for the award of a Research Studentship which enabled this work to be done under the supervision of Professor P. T. Thomas, Department of Agricultural Botany, U.C.W., Aberystwyth, to whom grateful acknowledgment is made. I also wish to thank Professor E. T. Jones, Director, Welsh Plant Breeding Station, for his interest in the problem and encouragement to pursue it to its completion since my appointment to the staff of the Station; also Dr D. J. Griffiths, Cereal Breeding Section, for helpful criticism in the preparation of this paper, and Miss Irene D. Rees for editing it.

\section{REFERENCES}

AGRICUltURAL Statistics. I882-1953. H.M.S.O.

AKDIK, s., AND MÜNTZING, A. 1949. New cases of segmental interchange and some other meiotic irregularities in rye. Hereditas, $35,67-76$.

ARMstrong, J. M., AND white, w. J. I935. Factors influencing seed setting in alfalfa. F. agric. Sci., $25, \mathrm{I} 6 \mathrm{I}-\mathrm{I} 79$.

DARLington, C. D., AND LA COUR, L. F. 1947. The Handling of Chromosomes. Allen and Unwin, London, pp. I8o.

DARLington, C. D., AND MAther, K. 1949. The Elements of Genetics. Allen and Unwin, London, pp. 446.

Darwin, Charles. 1900. Cross- and self-fertilization of plants. 2nd ed. London : J. Murray, pp. 487.

FYFE, J. L., AND BAILEY, N. T. J. 1951. Plant breeding studies in leguminous forage crops. I. J. agric. Sci., $41,371-378$.

Garner, F. 1945. The growing of field beans. Agric. Progr., 20, 26-30.

GLICK, D. 1949. Techniques of Histo- and Cyto-Chemistry. Interscience, New York, pp. 531 .

GRIFFITHS, D. J., AND ROWLANDS, D. G. Unpublished data.

Johnsson, ж. 1944. Meiotic aberrations and sterility in Alopecurus myosuroides. Huds. Hereditas, 30, 469-566.

LAMM, R. 1936. Cytological studies on inbred rye. Hereditas, 3r, 21 7-240.

LuNdeuist, A. I954. Studies on self-sterility in rye, Secale cereale L. Hereditas, 40 , 278-294.

LLNDQuist, A. 1955. Genetics of self-incompatibility in Festuca pratensis Huds. Hereditas, 4I, 518- j20.

MAEDA, T. I930. On the configurations of gemini in the pollen mother cells of V. faba L. Mem. Coll. Sci. Kyoto, B, 5, 125-1 37.

MCLEISH, J. 1953. The action of maleic hydrazide in Vicia. Heredity, Suppl., 6, I 25-147.

MÜ.Ntzing, A., AND AKDiK, s. 1948. Cytological disturbances in the first inbred generations of rye. Hereditas, $34,48 j-509$.

Mï:Ntzing, A., AND PRAKKen, R. I94I. Chromosomal aberrations in rye populations. Hereditas, 27, 273-308.

PEDERSEN, M. W. I953. Seed production in alfalfa as related to nectar production and honeybee visitation. Bot. Gaz., I15, I29-1 38 .

PICARd, J. 1953. Recherches sur la Feverole. Ann. de l'Amelioration des Plantes. Ser. B, 57-106.

RFES, H. 1955. Genotypic control of chromosome behaviour in rye. I. Inbred lines. Heredity, 9, 93-I 16.

REFS, H., AND THOMPSON, J. B. 1955. Localisation of chromosome breakage at meiosis. Heredity, 9, 399-408. 
REISCH, W. 1952. Variabilitatsstudien an V. faba L. Z.f. Acker-und Pflanz., 94, $281-306$.

stebbins, G. L. 1950. I'ariation and Evolution in Plants. Columbia Univ. Press, New York, pp. 643.

upсотт, м. 1937. Timing unbalance at meiosis in the pollen-sterile Lathyrus odoratus. Cytologia, Fujii Jubilaci Volumen. pp. 299-310.

WHITEHEAD, W. L., AND DAVIS, R. L. 1954. Self- and cross-compatibility in alfalfa (Medicago sativa). Agron. 7., $46,452-456$. 